\title{
Parenting style was associated with hyperactivity in school aged boys
}

\author{
Woodward L, Taylor E, Dowdney L. The parenting and family functioning of children with hyperactivity.J Child Psychol Psychiatry \\ 1998 Feb;39:161-9.
}

\section{Question}

Which parenting and family life factors are associated with hyperactivity in schoolchildren?

\section{Design}

Case control study.

\section{Setting}

16 schools in London, UK.

\section{Participants}

30 boys (mean age 9 y) who were 7-10 years of age, had hyperactivity but no emotional disturbance according to the Rutter A and B Scales, did not have mental retardation, and whose parents were able to complete the self report measures. 28 boys (mean age $9 \mathrm{y}$ ) who lived in the same area and had no hyperactivity or emotional disorder were in the control group.

\section{Assessment of risk factors}

Parenting attitudes and behaviour were assessed using the ChildRearing Practices Report, which rated negative affect and parenting styles, and a semistructured interview, which rated coping efficiency, disciplinary aggression, sensitivity, and interparental consistency. Family functioning was assessed by the General Health Questionnaire, Dyadic Adjustment Scale, and Significant Others Scale. Potential confounding factors were assessed. Interviewers were unaware of the children's diagnostic status.

\section{Main outcome measure}

The diagnosis of hyperactivity was confirmed using the Parental Account of Children's Symptoms Interview and parent and teacher rating scales derived from DSM-III-R diagnostic criteria.

\begin{abstract}
Main results
In unadjusted analyses, an association existed between increased hyperactivity and parental negative affect $(\mathrm{p}<0.01)$, less authoritative parenting style $(\mathrm{p}<0.01)$, inefficient parental coping styles $(p<0.001)$, use of disciplinary aggression $(p<0.001)$, less parental sensitivity $(\mathrm{p}<0.05)$, poorer mental health in parents $(\mathrm{p}<0.001)$, and less social support for the family $(\mathrm{p}<0.05)$. Hyperactive boys were more likely to have a conduct disorder $(\mathrm{p}<0.05)$ than boys in the control group. When results were adjusted for conduct disorder and parental mental health, hyperactivity was associated with inefficient parental coping styles $(\mathrm{p}<0.05)$ and use of disciplinary aggression $(\mathrm{p}<0.05)$ but not with negative affect, authoritative parenting styles, or parental sensitivity (table). Logistic regression showed that disciplinary aggression was the best predictor of hyperactivity and correctly classified $80 \%$ of hyperactive boys and $79 \%$ of controls.
\end{abstract}

\section{Conclusion}

Parental risk factors for hyperactivity in boys were the use of disciplinary aggression and inefficient coping styles.

Associations between parenting qualities and hyperactivity after adjustment for child conduct disorder and parental mental health

\begin{tabular}{lll}
\hline Parenting quality & Odds ratio & $95 \%$ CI \\
\hline Inefficient coping style & 3.32 & 1.24 to 8.91 \\
Use of disciplinary aggression & 2.54 & 1.24 to 5.20 \\
Negative affect & $1.65^{*}$ & 0.85 to 3.20 \\
Authoritative parenting style & $0.19^{*}$ & 0.03 to 1.10 \\
Sensitivity & $0.60^{*}$ & 0.34 to 1.05 \\
\hline
\end{tabular}

*Not significant.

Source of funding: Association of Commonwealth Universities.

For correspondence: $\operatorname{Dr}$ L Woodward, Christchurch Health and Development Study, Christchurch School of Medicine, PO Box 4345, Christchurch, New Zealand. Fax +6433720405.

\section{Commentary}

The study by Woodward et al shows that quality of parenting may contribute to the behavioural difficulties of hyperactive children. Unlike previous research which used structured clinical settings to observe parent-child interactions, this study used a community sample of non-referred children. Strengths of the study include (a) use of teachers and parents to identify hyperactive children and (b) assessment of parenting and family life factors by interviewers who were unaware of which children had hyperactivity. The authors did not report on single parent situations, the presence of aggressive symptoms, or the use of medication to treat attention deficit hyperactivity disorder.

Establishing a causal association between parenting style and hyperactivity is difficult because of the correlational results. The authors acknowledged that behavioural demands of hyperactive chil- dren may make it more difficult for parents to identify problematic situations. Parents of hyperactive children were more clinically disturbed and reported less practical support from others than did parents of control children.

The authors also reported that differences in parenting persisted after the effect of conduct disorder was removed. This suggests that problematic behaviours of hyperactivity may influence parenting and contribute to the worsening of behaviour problems. To confound the issue further, 1 study has shown that the negative style of parenting among mothers of hyperactive children is more likely to be a consequence of hyperactivity than a cause.

Parental mental health was also identified as an important determinant of child behaviour. The authors acknowledged that a more detailed assessment of parental mental health is needed to clarify its relation with the behaviour of hyperactive children.

The relatively small sample size limited the study's statistical power. A larger sample that includes girls would be more representative. Finally, because parent-child interactions are dynamic, repeating the measures to determine the changes in parent-child conflicts over time would be valuable.

Despite its shortcomings, this study highlights the need for comprehensive treatment for hyperactive children. Whatever the causal relation, negative parentchild interaction needs to be evaluated because it may affect children's self esteem and social competence and thus exacerbate their symptoms. ${ }^{1}$

Chris McDonald, RN, BHSc(N) Health Services Nurse Child and Parent Resource Institute London, Ontario, Canada

1 Hechtman L. Can J Psychiatry 1996;41:350-60. 